\title{
Biodegradation and Toxicological Evaluation of Lubricant Oils
}

\author{
Ivo Shodji Tamada, Paulo Renato Matos Lopes, Renato Nallin Montagnolli and Ederio \\ Dino Bidoia \\ Departamento de Bioquímica e Microbiologia; Universidade Estadual Paulista "Júlio de Mesquita Filho"; Av. 24- \\ A, 1515; 13506-900; Rio Claro - SP - Brasil
}

\begin{abstract}
The aim of this work was to compare different toxicity levels of lubricant oils. The tests were performed using the earthworm (Eisenia andrei), arugula seeds (Eruca sativa) and lettuce seeds (Lactuca sativa), with three types of contaminants (mineral lubricant oil, synthetic lubricant oil and used lubricant oil) for various biodegradation periods in the soil. The toxicity tests indirectly measured the biodegradation of the contaminants. The samples were analyzed at t0, t60, t120 and t180 days of biodegradation. The used lubricant oil was proved very toxic in all the tests and even after biodegradation its toxicity was high. The mineral and synthetic oils were biodegraded efficiently in the soil although their toxicity did not disappear completely after 180 days.
\end{abstract}

Key words: Toxicology, biodegradation, lubricant oil, toxicity bioassay

\section{INTRODUCTION}

Petroleum is a complex substance, featuring a wide range of molecular sizes, mostly comprising of aromatic hydrocarbon, alkanes, and compounds, which appear in a smaller quantity containing oxygen, nitrogen and sulfur (Fetter 1993). It is originated from bitumen from mother-rocks, which determines its composition. The usage and disposal of oil and its derivatives are kept under strict controls due to the fact that it is a relatively new substance to the environment. Still, it is a product of wide circulation and high contamination potential. The resolution 362 of National Environment Council (CONAMA) of Brazil regulates the usage and disposal of new and used lubricant oil.

The chemical characteristic of xenobiotic and characteristics of the environment determines how the xenobiotic change concentration and toxicity would vary. A xenobiotic can bioaccumulate, biodegrade or biotransform. Additional knowledge of such substances is important for the development of new drugs (Stine and Brown 1996; Landis and Yu 1995; Saval 2000).

Eco-toxicology studies have shown harmful effects of the chemical agents on living beings and on the environment (Stine and Brown 1996). According to Landis and $\mathrm{Yu}$ (1995), the environmental toxicology is a relatively new discipline and has multidisciplinary as a main characteristic.

Both acute and chronic toxicity tests are performed to comparatively evaluate toxicity of the substances.

By using the relevant organisms, such as fish, daphnia, rats, birds and seeds (Stine and Brown 1996; Landis and Yu 1995; Mariano 2007), the specific toxicity of a chemical compound can be evaluated.

\footnotetext{
*Author for correspondence: ederio@rc.unesp.br
} 
Due to its low cost and reasonable sensitivity, the germination of seeds is an important toxicology test and is a practical resource to indicate the qualitative presence of the toxic or organic inhibitors (Lopes et al. 2010). Wang and Keturi (1990) reported that phyto-toxicological tests using Lactuca sativa seeds were effective, since it was a sensitive organism and it has high germination rate.

Another widespread toxicity test uses earthworms (Eisenia foetida) as described by the Organization for Economic Cooperation and Development (OECD), Guide for chemical testing No. 207 (OECD 208 1984) and by Wei Liu et al. (2009).

Along with the toxicology studies that aim to remediate the situation caused by the humans, methods of control and impact assessment are often performed as well. One of the most used and studied methodologies is the bioremediation, which is the use of microorganisms to degrade a pollutant and the final products of bioremediation are mainly water and carbon dioxide (Montagnolli et al. 2009; Gutiérrez-Rojas 2000).

Poly-aromatic hydrocarbons are formed primarily by the carbon and hydrogen, i.e., they are the compounds capable of biodegradation. They are also mineral oil lubricant components considered to be carcinogenic, therefore, may affect the living organisms (Cotton et al. 1997). This is why it is important to know the destination and persistence of these compounds in nature (Shogren et al. 2004). A tolerable limit of those compounds may be calculated through the toxicological tests by using the sensitive organisms.

Lubricant oil behavior in environment along with its properties is a source for the development of new fluids (Eisentraeger et al. 2002). Thus, studies on the lubricants with lower environmental impact and faster biodegradation capacity have become a useful alternative (Basu et al. 1998; Goyan et al. 1998). That is why there is the development of synthetic and semi-synthetic lubricant oils.

This study aims to analyze the toxicity of automotive lubricant oils (mineral, synthetic, and used lubricant oils) during a set biodegradation period in the terrestrial environment. The toxicological levels during the biodegradation period were observed through the tests using the following organisms: Eruca sativa (arugula), Lactuca sativa seeds (lettuce) and Eisenia andrei (earthworm).

\section{MATERIALS AND METHODS}

The soil used in the toxicity bioassays was a sandstone type (grain size from $0.59 \mathrm{~mm}$ to 1.0 $\mathrm{mm}$ ) obtained at UNESP campus in the town of Rio Claro/São Paulo - Brazil.

The following oil types were used in the experiments without any kind of mixture: Superior mineral lubricant oil Havoline SJ, SAE 25W-50 Texaco, synthetic lubricant oil Lubrax SW-40 Petrobrás and used lubricant oil collected in oil changing places (gas stations or specialized garages), which made impossible to define the brand or type of oil.

For the biodegradation, it was necessary to obtain the potentially biodegrades microorganisms, so the inoculum was buried from March to September 2009 during the dry season. The selection of the microorganisms was made through a natural selection, which was "forced" by the inoculum.

Inoculations were buried in the Experimental Garden located near the Institute of Bioscience at UNESP Rio Claro, São Paulo - Brazil.

The equipment used in the study were: Chyo model JK200 analytical balance; Gehaka model BG440 semi-analytical balance; Marconi model MA403 type B.O.D. germination chamber; pipettes; plastic bags; beakers and 1, 0.59 and 0.35 mm sieves.

Three organisms were used for toxicity tests: Eruca sativa seeds (arugula), Lactuca sativa seeds (lettuce) and Eisenia andrei (earthworms).

An initial experiment was undertaken to obtain the reference concentrations to be used. The tested concentrations were: $0.5 \mathrm{~mL}$ of oil in $100 \mathrm{~g}$ of soil, $1.0 \mathrm{~mL}$ of oil in $100 \mathrm{~g}$ of soil, $5.0 \mathrm{~mL}$ of oil in 100 $\mathrm{g}$ of soil and $10.0 \mathrm{~mL}$ of oil in $100 \mathrm{~g}$ of soil. A single concentration was chosen to compare the effects of different types of oil and various biodegradation periods. Basal concentration was analyzed in three toxicity tests. The variations in the toxicity were monitored during the biodegradation period.

This study allowed an indirect evaluation of microbial metabolism efficiency in the contaminants by measuring the biodegradation process in toxicity tests.

Inoculum soil was collected according to the Technical Standards L6.245 - "Soil - collection and sample preparation Procedures" (CETESB 1984; Montagnolli et al. 2009).

The inoculum was a mixture of oil or biodiesel, surfactant (Tween 80), distilled water and soil 
according to the following proportions: $7.5 \mathrm{~mL}$ of contaminant (oils), $0.15 \mathrm{~g}$ of surfactant, $6.25 \mathrm{~mL}$ of distilled water and $100 \mathrm{~g}$ of test soil. The inoculum was prepared based on Lopes and Bidoia (2009) and Montagnolli et al. (2009).

For each type of contaminant, the procedure was performed as follows: $4800 \mathrm{~g}$ of sand was mixed with $360 \mathrm{~mL}$ of contaminant, $300 \mathrm{~mL}$ of distilled water and $7.2 \mathrm{~g}$ of surfactant (Tween 80). After homogenization, it was divided into four equal parts: the initial experiment $(\mathrm{t} 0)$ and other three parts to test the remaining biodegradation periods (t60, $\mathrm{t} 120$ and $\mathrm{t} 180$ days of biodegradation).

For the biodegradation in the environment, it was necessary to bury the inoculum in plastic bags. The bags were stuck with a pin so that the inoculum had contact with the ground, but no risks of wasting material or contaminating its surroundings. Plastic bags were buried at a $15 \mathrm{~cm}$ depth.

Germination tests using the seeds of E. sativa (arugula) and $L$. sativa (lettuce) were conducted as described by Lopes et al. (2010). Three plastic coffee cups (cup $50 \mathrm{~mL}$ ) containing $50 \mathrm{~g}$ of soil were used for each soil sample. Ten seeds of arugula were placed in each cup and $2.0 \mathrm{~mL}$ of deionized water were added and the soil was covered with a PVC film. The experiment was carried out in chamber at $22{ }^{\circ} \mathrm{C}$ for $72 \mathrm{~h}$ and germination could be observed. Simultaneously, a soil as negative control was made without any type of oil to test the seeds viability. The test was performed in initial, intermediate and final stages of the experiment to verify if the toxicity of the sample decreased with the treatment over time.

The same procedure was used for the lettuce seeds, with different incubation periods. The experiment was carried out maintained for $120 \mathrm{~h}$ in a BOD incubator at $22{ }^{\circ} \mathrm{C}$ for $120 \mathrm{~h}$. Simultaneously, a negative control was made, containing only soil without any type of oil to test the viability of the seeds used to in the toxicity testing. In the bioassay using $L$. sativa seeds, the data were corrected using modified Abbot formula, which allowed to check the efficiency of an insecticide (Abbott 1925), and in this case, it was used to evaluate the "effectiveness" of the contaminant in inhibiting seed germination.

Abbott's formula allows us to obtain the efficiency percentage, \%E (Abbott 1925). The adapted formulas: $I \%=((C-T) \times 100) / C$, where $I \%$ is the inhibition percentage, $C$ is the number of germinated seeds in the negative control and $T$ is the number of germinated seeds in the treated sample. The toxicological evaluation of this bioassay considered the agent: toxic when presenting germination inhibition above 40\%, onset of toxicity when presenting germination inhibition of $10 \%$ to $40 \%$ and not toxic when present inhibition to $10 \%$ (Lopes et al. 2010).

The toxicity test using Eisenia andrei was performed based in Wei Liu et al. (2009), Lopes et al. (2010) and Brazil (1988) with adaptations.

The adjustments were the base substrate and the incubation period. The substrate used was sandy soil and the incubation period was $168 \mathrm{~h}$ instead of amorphous silica and $336 \mathrm{~h}$ incubation.

\section{RESULTS AND DISCUSSION}

The pilot experiment, which used the concentration of $10.0 \mathrm{~mL}$ of lubricant oil to $100 \mathrm{~g}$ of soil showed a $100 \%$ mortality rate of $E$. andrei and high germination inhibition of the seeds of $L$. sativa and E. sativa. Therefore, the concentration of $10 \mathrm{~mL}$ of contaminant (oil lubricant) for each $100 \mathrm{~g}$ soil was considered too toxic due to the mortality rate of $100 \%$ for the E. andrei, so a smaller concentration of $7.5 \mathrm{~mL}$ of lubricating oil $100 \mathrm{~g}$ of soil was chosen for the toxicity tests.

The bioassay using seeds of E. sativa showed a decrease in the toxicity levels of both mineral and synthetic lubricant oils as the biodegradation period was prolonged, and a high and constant level of toxicity for the used lubricant oil in almost all the biodegradation periods (Fig. 1).

In the tests using E. sativa, the oils presented initially high toxicity, reaching above $80 \%$ inhibition levels in all cases (Fig. 1). For the mineral oil, there was an increase in toxicity at t60 days, but a decrease in remaining time. The new synthetic lubricant oil had its toxicity diminished after the adaptation period and the used lubricant oil's toxicity remained high over time. This fact is reported by Lopes et al. (2010), where the toxicity of mineral and synthetic oil decreased after 90 days of biodegradation and the used oil remained high toxicity before and after biodegradation.

In the tests with L. sativa (Fig. 2) the mineral oil initially presented high toxicity, which decreased after 120 days. At 180 days the toxicity level increased, showing that at this time, secondary compounds, which were highly toxic for the testing organisms, might have arisen (Lopes et al. 2010). The synthetic lubricant oil initially showed 
high level of toxicity, but it decreased over time and after 60 days of biodegradation, its toxicity remained low and constant (close to 20\% inhibition). The used lubricant oil, on the other hand, showed an increase in the toxicity level, especially after 60 days of biodegradation (Fig. 2).

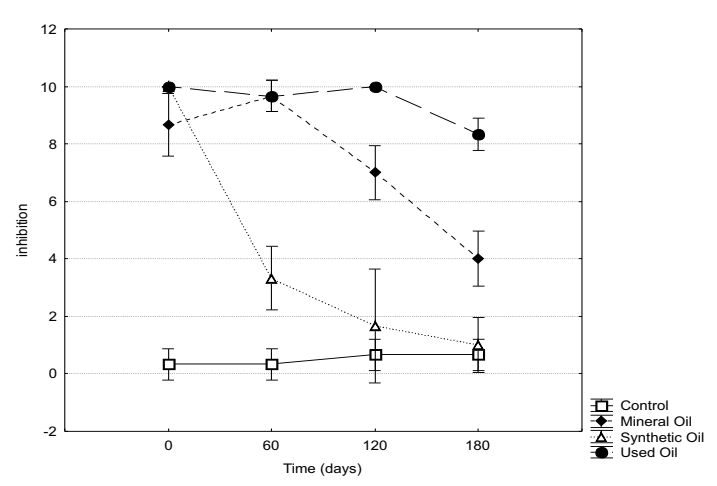

Figure 1- Germination Inhibition of Eruca sativa's seeds on three days in soils that biodegraded by $\mathrm{t} 0, \mathrm{t} 60, \mathrm{t} 120$ and $\mathrm{t} 180$ days.

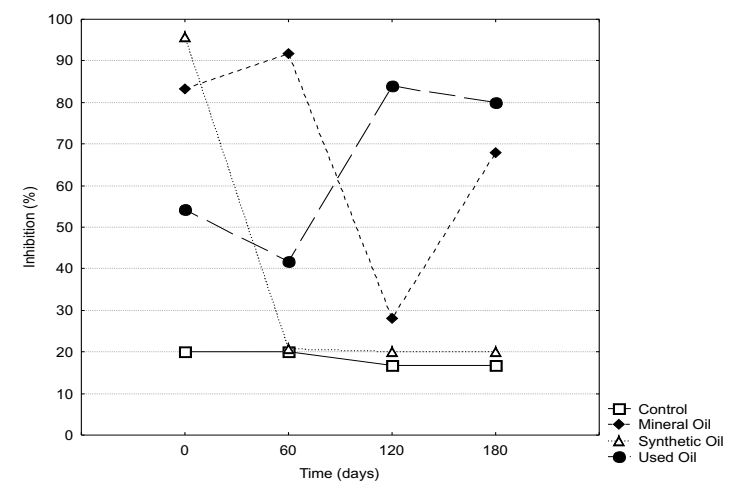

Figure 2- Germination Inhibition of Lactuca sativa's seeds on five days in soils that biodegraded by t $0, \mathrm{t} 60, \mathrm{t} 120$ and t 180 days.

Tests with E. andrei (Fig. 3) showed that 180 days of biodegradation were efficient to diminish the toxicity of the mineral lubricant oil and the synthetic lubricant oil. The first one presented no toxicity at the end of this period and the synthetic lubricant oil presented $10 \%$. The used lubricant oil, on the other hand, did not show toxicity decrease.

The mineral lubricant oil is formed by a mixture of different molecules, so it shows difference in biodegradation and toxicity compared to synthetic lubricant oil. Synthetic oil presents known structures, it is composed of molecules produced in refinery and in many cases it becomes more biodegradable (Lopes et al. 2010; Lopes and Bidoia 2009). According to Lopes et al. (2010) e Lopes and Bidoia (2009), the used lubricant oils are biodegraded more easily, followed by the semi-synthetic oil and finally, the mineral oil. In this study, the oil used for the tests were synthetic rather than semi-synthetic. The fact that one material is more biodegradable than the other does not have a direct relationship with its toxicity, since it depends on the formation of side compounds during its biodegradation. 


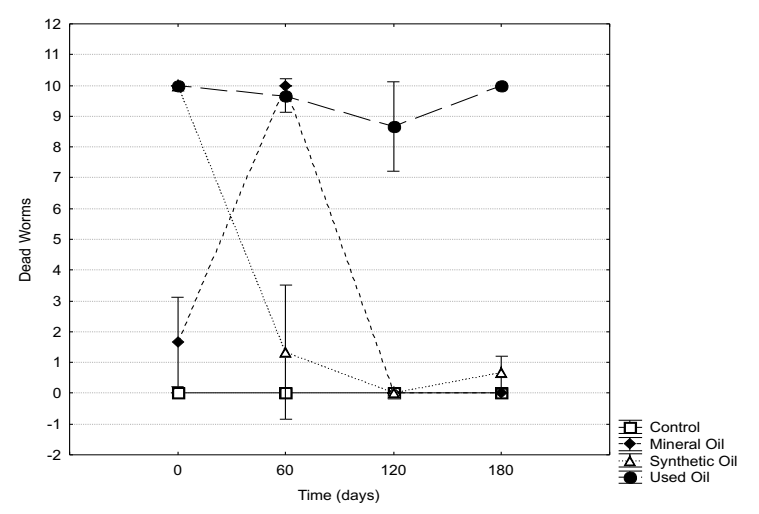

Figure 3- Death of Eisenia andrei during seven days in soils that biodegraded by t0, t60, t120 and t180 days.

In general, used lubricant oils present heavy metals, which comes from vehicles engine usage. This causes its toxicity to be high in biodegradation periods (Fig. 1, 2 and 3) mainly in tests with $E$. sativa and $E$. andrei, despite the fact that oil molecules are more degraded due to the engine's high temperature and compression levels (Eisentraeger 2002; Lopes and Bidoia 2009). The fact that the chain is more or less degraded does not necessarily mean that the toxicity level is lower. In many cases, the fact that a substance is more degraded makes it more available to soil organisms.

The used lubricant oil did not show toxicity decrease. This may be explained by the presence of heavy metals, which do not suffer degradation, maintaining the high toxicity levels. Therefore a longer biodegradation period or implementation of a bioaugmentation would be a reliable solution for this problem.

Although this study shows only analysis of seeds germination, others studies reported that toxic substances can affect the growth of root and hypocotyl and its influence varies with organismtest used (USEPA 1996).

\section{CONCLUSION}

Out of the tested oils, the synthetic one was the most biodegradable one due to the fact that it is formed by molecules which are predominantly formed by only one type of chemical structure. As the microorganisms got adapted to the substrate (synthetic oil) the biodegradation was accelerated and in 60 days the toxicity was reduced in all samples.
Biodegradation proved to be effective for mineral and synthetic oils according to $E$. andrei tests. Used oil, however, had its toxicity level close to $100 \%$ for all biodegradation periods.

To perform a bioremediation of lubricant oils in soil, the biodegradation period should exceed six months, except for the synthetic oil, which may have its toxicity dramatically reduced in just 60 days.

As for the used lubricant oil, the solution could be the bioaugmentation process, which means that heavy metals would be removed from the soil so that the toxicity of environment could be diminished.

\section{ACKNOWLEDGEMENTS}

The authors thank ANP/PRH05-Petrobrás, FUNDUNESP, CAPES, Hélio Hermínio Checon, Luiz Motohissa Yojo and Angela Satiko Yojo.

\section{REFERENCES}

Abbott WS. A method for computing the effectivness of an insecticide. J Econ Entomol. 1925; 18: 265-267.

Brazil. Evaluation of the toxicity to soil organism: earthworms Eisenia foetida. In Manual of tests for evaluation the ecotoxicology of chemical agents. Ministry of interior- Special Secretary of Environment.1988; Brasília, D5.1-7.

Basu B, Singh MP; Kapur GS, Nazakati Ali, Satry MI S, Jain SK, et al. Prediction of biodegradability of mineral based oils from chemical composition using artificial neural networks. Tribol Int 1998; 31: 159168. 
CETESB - Environmental Sanitation and Technology Company (1984), Soils- Collection and Sample Preparation - Procedure. Technical Standard L6.245. 1984; São Paulo, Brazil.

CONAMA - National Counsel of the Environment. Resolution $n^{\circ} 362$. 2005; 121(01): 128-130.

Cotton FO, Wishman ML, Goetzinger JW, Reynolds JW. Analysis of 30 used motor oils. Hydrocarb. Process. 1997; 22:131-140.

Eisentraeger A, Schimidt M, Murrenhoff H, Dott W, Hahn S. Biodegradability testing of synthetic ester lubricants - effects of additives and usage. Chemosphere. 2002; 48: 89-96.

Fetter CW. Contaminant Hydrogeology. New York: Macmillan; 1993.

Goyan RL, Melley RE, Wissner PA, Ong WC. Biodegradable lubricants. Lubr. Eng. 1998; 54: 1017.

Gutiérrez-Rojas M. Increasing Bioavailability of recalcitrant molecules in contaminated soils. In: Environmental biotechnology and cleaner bioprocesses. London: Taylor and Francis Limited; 2000. 167-177.

Kitamura Y, Nishikawa A, Furukawa F, Nakamura H, Okazaki K, Umemura T, et al. A subchronic toxicity study of shea nut color in wistar rats. Food Chem Toxicol. 2003; 41: 1537-1542.

Landis WG, $\mathrm{Yu} \mathrm{MH}$. Introduction to environmental toxicology: impacts of chemical upon ecological systems. Florida: Lewis Publishers. 1995.

Lopes PRM, Montagnolli RN, Domingues, RF, Bidoia ED. Toxicity and biodegradation in sandy Soil contaminated by lubricant oils. B Environ Contam Tox. 2010; 84: 454-458.

Lopes, PRM, Bidoia ED. Evaluation of the biodegradation of different types of lubricant oil in liquid medium. Braz Arch Biol Techn. 2009; 52: 1295-1290.
Mariano AP, Kataoka APAG, Angelis DF, Bonotto DM. Laboratory study on the bioremediation of diesel oil contaminated soil from a petrol station. Braz J Microbiol. 2007; 38(2): 346-353.

Montagnolli RN, Lopes PRM, Bidoia ED. Applied models to biodegradation kinetics of lubricant and vegetable oils in wastewater. Int Biodeter Biodegr. 2009; 63: 297-305.

Morais EB, Tauk-Tornisielo SM. Biodegradation of Oil Refinery Residues Using Mixed-Culture of Microorganisms Isolated from a Landfarming. Braz Arch Biol Techn. 2009; 52:.1571-1578.

OECD - Organization for Economic Cooperation and Development Guideline for testing of chemicals. 1984; n⿳2 208.

Saval S. Biorremediation: clean-up biotechnologies for soils and aquifer. In: Environmental biotechnology and cleaner bioprocesses. London: Taylor and Francis Limited; 2000. 155-166.

Shogren RL, Petrovic Z, Liu Z, Erhan SZ. Biodegradation behavior of some vegetable oil-based polymers. J Polym Environ. 2004; 12.

Stine K, Brown TM. Principles of Toxicology. Boca Ratton: CRC Press; 1996.

USEPA. United States Environmental Protection Agency (EPA 712-C-96-154) Ecological Effects Test Guidelines - OPPTS 850.4200 - Seed Germination/Root Elongation Toxicity Test. 1996.

Wang W, Keturi PH. Comparative seed germination tests using ten plants species for toxicity assessment of metal engraving effluent samples. Water Air Soil Poll. 1990; 52: 369-376.

Wei Liu, Lu-Sheng Zhu, Jun Wang, Jin-Hua Wang, Hui Xie, Yan Song. Assessment of the genotoxicity of endosulfan in earthworm and white clover plants using the comet assay. Arch Environ Com Tox. 2009; 56: 742-746. 